\title{
HOW "KHMER PRODUCT" IS MADE THROUGH DEVELOPMENT PROCESS: FOCUSING ON CHANGING THE VALUE OF AGRICULTURAL PRODUCTS IN CONTEMPORARY CAMBODIA
}

\author{
Sayaka Akiho
}

University of Tsukuba

Palnet Kasuga 201, 3-2-6 Kasuga, Tsukuba city, Ibaraki 305-0821 Japan

Email: akiho.sayaka.gt@u.tsukuba.ac.jp

Citation: Akiho, S. 2020. How "Khmer product" is Made Through Development Process: Focusing on Changing the Value of Agricultural Products in Contemporary Cambodia. J. Asian Rur. Stud. 4(1): 71-87

\begin{abstract}
This study investigates some aspects of the socio-cultural changes that took place in contemporary rural Cambodia by focusing on production and marketing practices. It explores both the changing value crops and the transformation in agricultural production and trade among Khmer farmers after a new farming technology was introduced by a local NGO. The case study presented in this paper is a local NGO operating since 2001 in the rural area where the author has conducted fieldwork from 2005 to 2016. The NGO has introduced a new agricultural technique and tried to establish farmer organizations in village and national level. The yield crops produced with new technology was authorized by NGOs and given the new commodity value of 'Khmer organic products. This signifies that dissemination of new agricultural techniques brings not only change in the production itself but imposes a new system for marketing crops and images of Khmer products. Therefore, dynamically transformed the social relationship patterns not only among the farmers, but with outsiders as well, including development promoters.
\end{abstract}

Keywords: Contemporary Cambodia; Rural development; Khmer products; Value of Agricultural Products

\section{Introduction}

What does trade mean for local people? Generally, policy makers in least developed countries (LDCs) tend to consider international trade an effective measure that reduces poverty and stimulates economic growth. From their point of view, it helps create jobs, raise living standards and gives people opportunities to improve their lives. That is to say, they believe that development is promoted through integration into national and international capitalist market. Because of that thought, policy makers and some economists require the promotion of trade as a part of development in LDCs. On the other hand, international trade has been criticized as expanding inequality between 
developed countries and LDCs in dependency theories. However, the viewpoint of local people in LDCs is different from either of the above arguments on international trade.

This paper highlights the local peoples' view and examines how their perception of international trade of Khmer people in cultural and religious contexts. Local voices concerning the economic situation that lie outside the scope of the indigenous and local power spheres provide thought-provoking perspectives on the discussion about world trade.

First, the author describes the present situation surrounding the local people. Although the concept of international trade is vague for the most of them, it does not mean they have no idea what kind of impact trade has. People understand this impact through more concrete concepts that are embedded in the local cultural economic system.

People live in a world where complexity and interconnectedness are increasingly prevalent, 'based on financial commitments, commodity edge disseminations, and political negotiations and struggles that are transnational in character' (Long 1996). Tim Mitchell calls attention to the fact that the transformation of the "processes of exchange that economists had always studied made possible new forms of value, new kinds of equivalence, new practices of calculation, new relations between human agency and the non-human, and new distinctions between what was real and the forms of its representation' (Mitchell 2002).

Before entering upon a discussion, we need to consider who the local people are. Some scholars use 'local people' and 'government' synonymously in discussing the relationship between international trade, local society, and the people there. Government is, of course, just one portion of the local people. The ideas of government officials are visible and easily readable because they are the main actors who publish policy papers and their ideas are widely publicized in the media. In addition, they are the main actors who engage in policy-making and negotiations at the international conferences. By contrast, the ideas (perceptions) of farmers, garment factory workers and fisheries workers are more invisible and inaccessible. If trade benefits the country and has an impact on local daily life, we should listen to the voices of local people when considering international trade policy.

\section{Research Method}

This research based on ethnographic study from 2013 to 2018 in 11 communities of 8 provinces of Cambodia (Takaev, Kampot, Kampong Speu, Preah Sihanouk, Kampong 
Chhnang, Battambang, Banteay Meanchey, and Kandal) and the capital, Phnom Penh. In 2013 field research, I conducted 368 household interviews and 30 group interviews with using a questionnaire and also conducted participant observation; in total, listened to the voices of 668 people and given the constraints of time and resources, we purposely selected 11 communes to represent the most prevalent groups of people, covering the diverse range of people and conditions in Cambodia. The eight provinces have different agro-ecological conditions, including a rice farming area, a fishing village, a pepper producing area, and Phnom Penh and Kandal Province which have communities of textile factory workers from other provinces. The author analyzed how changed the buying and selling custom and local people's perception from voices of the people.

\section{Result and Discussion}

\subsection{Changing the buying and selling custom of agricultural products in Cambodia}

In Cambodia, agriculture accounts for $36 \%$ of GDP and employs $51 \%$ of the labor force (MAFF 2012). According to a report released by the World Bank, in spite of industries and services that contribute significantly to the economy, $34.5 \%$ of Cambodians suffer from poverty, and most of them are farmers (World Bank 2006, 2012). Agriculture is a key sector in the national economy, and for Khmer farmers, it is a key to poverty reduction.

Cambodia shares borders with three countries - Vietnam, Thailand, and Laos-and traditionally these countries have established formal and informal economic relationships. Officially, Cambodia's main import sources are China, Thailand, Vietnam, and Taiwan, and its main exports go to Hong Kong, United States, UK, Germany, Canada and Singapore, etc. Import commodities include petroleum products, cigarettes, gold, construction materials, machinery and motor vehicles. Export commodities include clothing, timber, rubber, rice and fish. Many kinds of goods are also freely smuggled between neighboring countries. It has been estimated that about a million tons of paddy rice were smuggled to neighbor countries, since Cambodia lack of high quality rice millers and has hindered by unfavorable trading conditions, such as informal fees and high transport and processing costs (Kem et al., 2001). These figures are undocumented; however, this custom has been consistently practiced historically, and it has been a daily sight in the border area. For example, a local market in the southern rice-producing area of Takaev Province has a variety of vegetables which are imported from Vietnam. In fact, there are informal transactions by Vietnamese and 
Cambodian brokers around the border area. They are operating small businesses in foods and other products for daily use including gasoline, rice, livestock and fertilizers. The local market offers various commodities and foods from abroad. Daily commodities like dishware, plastic chairs, clothing and electric appliances are made abroad. In the case of clothing, venders come to local markets several times a week and sell used clothing from places like Korea, China and Japan. As for electric appliances, local people say these come from abroad, but they do not have accurate information about the production region and the quality. Cheap imported goods with unreliable information flood the local market, but at the same time, it is also true that people benefit from them.

In my interview, $73 \%$ of farmers (271 persons) answered that their daily life is better than 5 years ago, and $76 \%$ of the e farmers interviewed ( 281 persons) said their life is better than 10 years ago. A farmer in Kampot Province (female in 40s) said that compared to 5 years ago, they have better roads and media services, such as mobile phone service. Moreover, compared to 10 years ago, they have enough agricultural tools to cultivate and have more business chances, they said. Another Kampot farmer (male in 50s) answered that not only do they have enough material and food but also that selling and buying products for daily use has become easier than before. Many farmers mentioned that changes in the method of buying and selling have made their everyday buying-selling practice easier than before. For example, in rural areas when farmers want to buy some products, they call the sellers in the local markets on their mobile phones, and later the seller delivers the products to the customer. Not only local people but also people in the capital (neak ti kron) can buy various products just by calling the seller on their mobile phones. The same holds true when they want to sell agricultural products or handicrafts to middlemen.

In addition to conducting transactions by mobile phone, market information has become more readily available through a mobile system. Traditionally, farmers have received rice price information from middlemen in the community. Recently in addition to that, a Market Information Service (MIS) with a limited number of commodities gathered from across the country is provided by the Ministry of Agriculture, Forestry, and Fisheries (MAFF). This information is also broadcasted several times each week on the radio from Phnom Penh and Battambang. This information system provided through mobile phones operates in cooperation with the Food and Agriculture Organization (FAO), which tracks prices as well as supply and demand conditions. It is said to fulfill an important and necessary function that has been used to good advantage by producers, 
traders, consumers, and relevant government institutions. As seen above, the flow of information related to agricultural production and marketing has been changing because of communication technologies.

In parallel with the enhancement of the information flow, people's lifestyles and life courses have also changed and have become diversified. Traditionally women and men, especially women who have not had access to education, often were expected to help their families with housework and agricultural work. Since the early 2000s, young people have been able to find jobs in garment factories in the capital or places abroad like Thailand, Malaysia and Korea. As a result, people have gained more opportunities to work and earn money.

Table 1. Brief Summary of Results (2013 Survey)

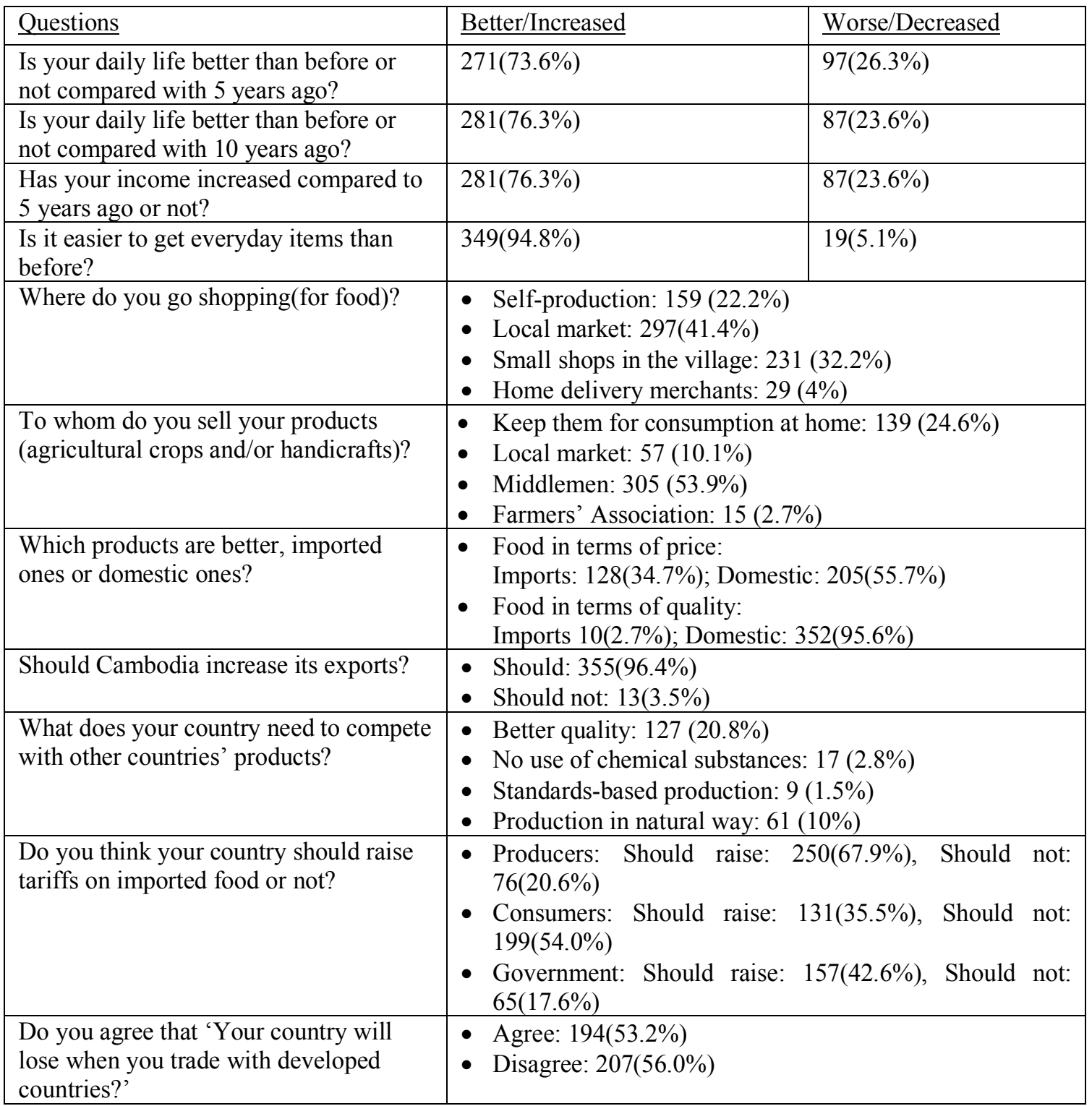




\subsection{Case Study}

With increasingly free flows of commodities, people, media and information, the boundary between the rural society and other areas seems to be disappearing. However, as the flows are extremely intense, they not only provide benefits to areas but also pose new kinds of 'risk'. Moreover, the flows promote reshaping of people's identities and form a new value of commodities. Under these circumstances, rural people see business chances in the competition in the global marketplace with their 'superior' domestic products. This section examines the specific cases of different agricultural endeavors - livestock, rice, pepper and the garment industry - and what local risk perception consists of and its effect on people's economic daily practices in rural areas.

\subsubsection{Livestock}

As mentioned earlier, around the border area, people and commodities are going back and forth every day between Vietnam and Cambodia, and people on both sides receive benefits from this activity. However, due to the increasing traffic of commodities and people, farmers are also confronting serious problems.

A swine disease called porcine reproductive and respiratory syndrome (PRRS) spread out to Cambodia from Vietnam in May 2010. In response, Prime Minister Hun Sen asked provincial authorities to suspend the importation of pigs from Vietnam and Thailand. However, he conceded that it would be impossible to completely stop the illegal importation of pigs from neighboring countries. He also noted that 'this order is not a violation of the rules of the World Trade Organization; it is a measure to protect the animals' lives and prevent from infectious disease'. He also urged pig vendors not to take advantage of any resulting supply shortfall by raising prices.

Thai swine exports to Cambodia rose from 2,273 pigs in 2007 to 866,199 in 2009 and were worth $\$ 45$ million that year. Regarding this issue, a farmer in Kampot province (female in 40s) said, 'The government should reduce imported animals to prevent diseases from other countries. So, I guess the government had better raise the import tariff to control the situation'. This narrative shows that, behind her opinion that the government should raise tariffs on imported food, there is concern over 'food safety'. Other farmers in Kampong Chnang (female in the 50s) and a middleman in Preah Sihanouk (female in the 60s) said, 'Sellers always cheat us. But, some people who sell products for the producers also tell lies about product qualities. So, nobody has corrected information about it' and 'They are good at cheating people. We need to check the products ourselves'. Another farmer 
in Takaev (male in 40s) said, 'When this problem occurred, many farmers were mad. So, they called a local radio station and responded with sharp criticism about the problem. They implicitly criticized the government which could not control this serious matter'. This shows that people do not trust the sellers or the quality of products they buy from sellers in the market because of the lack of reliable information. People also believe that PRRS occurred because the Vietnamese cheated Cambodian pig buyers, and moreover, they feel that they have no power or institutions to control the quality.

The case of the outbreak of the foot-and-mouth disease in 2007 also shows that imported pigs devastated Cambodian pig farmers. Pig farmers asked the government to slash import quotas. When this problem occurred, farmers cared about controlling of the diseases caused by infected imported pigs. Many farmers lost their pigs and suffered damage due to the spread of this disease. Even though the government tried to stop imports of Thai and Vietnamese pigs to control the spread of the disease, the supply cuts sent the prices through the roof. This meant that farmers suffered double damage, as producers and as consumers, because usually, people raise pigs to sell and not for home consumption.

Thus, farmers' voices are shaped by these everyday experiences which are constituted geographically and historically. The livestock agriculture of Cambodia and the livestock buying-selling customs were exposed to the influence of the plague. With the acceleration of the commodities flow, local people's need to control the risk brought by imported products has grown in recent years.

\subsubsection{Rice as 'White Gold'}

In Cambodia, farmers fall into two categories by the kinds of agricultural products they produce. One is neak srae, which literally means 'rice paddy people', and the other is neak chamkar, which means 'a field people'. As indicated by these category names, neak srae mainly engage in rice farming, and neak chamkar grow vegetables and rice in their fields. Traditional rural interests have given way to more complex environmental issues and other issues such as food quality and price changes.

Rice is the most important staple food of Cambodians; moreover, for them, it has various meanings in terms of subsistence, commercial activities and also its culture. Delvert, a French scholar of Cambodian society in the 1950s, said, 'The Cambodian is a peasant' in his study Le Paysan Cambodgien (Delvert 1961). This seems not to have changed even today because Cambodia is still a predominantly agricultural 
society, with about $85 \%$ of the people living in rural areas and more than a quarter of the population working in the agricultural sector. The majority of the rural population is farmers, cultivating rice mainly for subsistence.

Thailand and Vietnam are well-established rice exporting countries and are the two top rice exporters in the world. In the 1950s, indeed, Cambodia was one of the world's leading rice exporting countries. However, persistent civil war land degradation that reduced rice productivity because many of the rice fields were left uncultivated. Following this period, the main source of production growth from 1980 to 1994 was growth in rice although the yield remained below $1.5 \mathrm{t} / \mathrm{ha} .1$

Rice is mostly grown in the Tonle Sap Lake zone and the plain zone. The plain zone is the major producer of dry season rice, accounting for more than $75 \%$ of total paddy output and $80 \%$ of the total area (MAFF 2012). Dry season paddy cultivation remains an important component of rice cultivation, particularly for consumers. From 1994 to 2008, wet season rice production grew at 7.1\% per year, while dry season rice production grew at $5.8 \%$ per year. On average, Cambodia's rice yield has increased at a rate of $5.4 \%$ per year since 1994, from 1.6 ton/ha in 1994-1997 to 2.3 ton/ha in 2003-2008. The cultivation of rainy season rice reached 2.5 million hectares, with an average yield of $2.92 \mathrm{t} / \mathrm{ha}$, resulting in a total production amount of paddy rice of about 6.7 million tons. For dry season rice, over 0.47 million hectares were cultivated, with an average yield of $4.4 \mathrm{t} / \mathrm{ha}$ (MAFF, 2012).

Table 2: Rice Production in Cambodia, 2007-2011

\begin{tabular}{|c|c|c|c|c|c|}
\hline & 2007 & 2008 & 2009 & 2010 & 2011 \\
\hline $\begin{array}{l}\text { Cultivated Area } \\
\text { (ha) }\end{array}$ & $2,585,905$ & $2,615,741$ & $2,719,080$ & $2,795,892$ & $2,968,529$ \\
\hline $\begin{array}{l}\text { Harvested Area } \\
\text { (ha) }\end{array}$ & $2,566,952$ & $2,613,363$ & $2,674,603$ & $2,777,323$ & $2,766,617$ \\
\hline Yield (ton/ha) & 2.612 & 2.746 & 2.836 & 2.97 & 3.173 \\
\hline $\begin{array}{l}\text { Production } \\
(\mathrm{MT})\end{array}$ & $6,727,127$ & $7,175,473$ & $7,585,870$ & $8,249,452$ & $8,779,365$ \\
\hline $\begin{array}{l}\text { Rice Surplus } \\
\text { (MT) }\end{array}$ & $1,649,640$ & $2,025,033$ & $2,244,598$ & $2,516,752$ & $2,780,328$ \\
\hline $\begin{array}{l}\text { Paddy Surplus } \\
\text { (MT) }\end{array}$ & $2,577,562$ & $3,164,114$ & $3,507,185$ & $3,932,425$ & $4,344,263$ \\
\hline
\end{tabular}

Source : MAFF 2012. 
Table 3: Rice Yield in Cambodia and Neighboring Countries, 2000-2008

\begin{tabular}{l|c|c|c|}
\hline & Thailand & Cambodia & Vietnam \\
\hline $\begin{array}{l}\text { Yield 2006-08 average } \\
\text { (tons/ha) }\end{array}$ & 2.74 & 2.54 & 4.89 \\
\hline $\begin{array}{l}\text { Input use 2006-08 } \\
\text { Fertilizer (kg/ha) }\end{array}$ & 108 & $34-68$ & 220 \\
\hline $\begin{array}{l}\text { Irrigation (\%) } \\
\text { Export quantity } \\
\text { (thousand tons) }\end{array}$ & 33 & 20 & 46 \\
\hline Export price 2006-07 average (\$/ton) & 6483 & 2 & 4817 \\
\hline
\end{tabular}

Source: Bingxin and Xinshen 2011.

In the context of rural development, the government and NGOs have promoted new agricultural techniques and agricultural business in domestic and international markets. In our research, most of the farmers said that, despite climate change, their yields have been increasing thanks to improved farming techniques promoted by the government and NGOs. They added to that the fact that the buyers of rice have become more diversified than before.

A leading local NGO has popularized among farmers a new natural agricultural technique called System of Rice Intensification (SRI) and has purchased the resulting rice to sell in supermarkets and its organic shops and to export abroad. In conducting the project, the NGO expanded the volume of new agricultural knowledge and pointed out the health and cost problems of chemical fertilizers. The producers who adopt the SRI technique and pay the membership dues can sell their products to the NGO. Because the NGO has an inspection system, some farmers think it is complicated; however, they also feel it is profitable for them, especially given the pricing which the NGO sets.

A farmer in Battambang (male in 50s) said, 'We can get a higher yield than before because of new agricultural techniques that the NGO promoted'. A farmer in Kompong Chhnang (female in 40s) said, 'Comparing the current situation with the 1990s and early 2000s, there were only local middlemen as buyers in the commune back then. Now, we can sell rice to NGO, companies, and middlemen. It is much easier than before'. However, another farmer (male in 40s), answered, 'I want to sell paddy rice at a high price because now it's not enough for my family. Previously, I sold to an NGO because they gave an extra KHR200/kg more than local middlemen, but I stopped selling to them because they often delayed payment. 
This means they often "told a lie". In rural areas, if someone tells a lie, we will quit the relationship and never sell to them. This is the way of rural areas. They did not understand this; they just followed the urban way'. These cases show some benefit from an increase in the number of actors who sell, but others faced inconveniences. In a sense, farmers attach importance not just to having 'several buyers and prices to choose from' but also to 'the manner of the sale'.

In June 2010, the Council of Ministers approved the 'Policy Paper on the Promotion of Paddy Production and Rice Export' by the Committee on Economic and Financial Policies. The purpose of this policy is to promote agricultural development at a new pace and on a new scale that broadens and strengthens the foundation of economic growth while accelerating poverty reduction and improving people's livelihoods. The policy paper calls rice 'white gold' with emphasis on its commercial value in the international market.

Traditionally, rice cultivation was practiced mainly for home consumption, for sharing with relatives or neighbors, and for donating to temples or monks, and mainly indigenous species like srau krohom, etc., were cultivated. However, people have started to realize that rice is a high-value-added product thanks to the development projects of NGOs and the government. Cambodian rice (jasmine rice) is regarded as a valuable commodity in the international market, and Cambodian rice won the 2012 and 2013 World Best Rice Award at the global rice-tasting competition held at the World Rice Conference (WRC). Thus, the circumstances surrounding rice-farming agriculture in Cambodia have changed markedly in recent years. Outside appraisals, market strategies and agricultural policies related to rice have been internalized by farmers; some farmers have started to grow rice that is geared to the domestic and international markets.

\subsubsection{Pepper}

This section describes the case of pepper farming which is expanding satisfactorily because it qualified for the WTO's Geographical Indication (GI) status. Kampot Province is famous as a production center of pepper, which is characterized by its strong pungency and aromatic intensity. There are four kinds of pepper, black pepper, red pepper, green pepper, and white pepper. Green pepper is sold in the domestic market, while black, red and white peppers are exported to Australia and some European countries. Kampot Province has the Kampot Pepper Association, which has 152 members who are producers, and it was established with support from a local NGO. Kampot pepper is registered as GI by the Ministry of Commerce, and its production 
area is limited to Kampong Trach, Dang Tong, Toeuk Chhou, Chouk and Kampot city in Kampot Province, and also Kep city and Damnak Chang Aeur district of Kep Province. To be entitled to produce and sell Kampot pepper, the persons (producer, processor, packager, and seller) have to register with the association and be accredited. Declaration of volume produced is required for all members as well as registration of transactions. The traceability system is an important system for marketing in international trade. Moreover, random samples are taken to check the compliance of the product with the criteria that define Kampot pepper specificities.

The method of producing pepper is also based on the natural farming method. For example, farmers must use only natural fertilizers and Class II and III chemical insecticides, a standard that was set by WHO. The land used to produce pepper has to be declared by its owner, and the association checks the compliance of the parcel with the requirements of the GI. In addition to this, every producer has to sign a letter of commitment to follow the guidelines of specification and to be inspected at least once a year.

A member of the association said, 'Producing pepper according to the standards is difficult and complicated, but the price of it rose compared to before. Pepper that was previously USD3/kg is now USD18/kg'. Another member answered, 'There is not enough production to meet the level of international demand. We need to increase the planted area. I'm sure that Kampot pepper is becoming an essential crop for improving families' livelihood'.

Similarly, in our field survey, several farmers talked about 'standards' and 'contracts' as strategies for improving the quality of domestic agricultural products, increasing their income and improving their livelihood.

\section{Discussion: the value of Domestic and Imported Products - 'Safety' and 'Risk'}

How can we ensure that we are being supplied with food that is 'safe/riskfree'? How can we establish standards of 'safe/risk'? The WTO Agreement on the Application of Sanitary and Phytosanitary Measures (the 'SPS Agreement') concerns the application of food safety and animal and plant health regulations. It allows countries to set their standards, but it also states regulations must be based on 'scientific methods' of measurement.

Governments have to devise innovative strategies to deal with the innumerable risks to health and well-being. In this paper, the author presents a description of the cases that have caused a contextual, political and economic redefinition of 
domestic/foreign (self/other) which goes beyond the conventional agricultural and industrial modernization process. According to Beck (1992), postmodern society is facing a new state of human insecurity characterized by the fear of the dark side of progress. Because of the failure of modern social institutions to control the risks they created, risk rebounds as a largely defensive attempt to avoid new problems. Here, the term risk is used simply as a synonym for hazard or danger. However, he also discusses a perspective in which risk is viewed as socially constructed and mediated through the lens of social and cultural processes; he says, 'It is cultural perception and definition that constitutes risk' (Adam, Beck and Loon 2000).

The crisis surrounding BSE has been cited in the food risk literature as a classic illustration of 'manufactured risk' (Giddens 1999). Much of the literature on risk since the early 1990s has been concerned with an understanding of risk beyond the technical and scientific arenas and with a view of risk as a dynamic phenomenon, located within cultures, structures, institutes and individual worldviews; it includes a focus on 'everyday risk', i.e., the role of the notion of risk in people's routine activities and life planning strategies (Smith, Cebulla, Cox and Davies 2006; Tulloch \& Lupton 2003, Douglas 1983). These socio-cultural approaches to risk try to describe more complex and dynamic processes of risk issues in everyday life. Risk knowledge is seen as historical and local, as constantly contested and as a subject to disputes and debates over their nature, their control and who is to blame for their creation.

Thus, the carving up of reality and labeling of the components is characteristic of scientific knowledge and is a central feature of the standard approach to policy intervention. This approach typically leads to separations that do not correspond with local perceptions. Tampering with people's values and life-worlds may occur in an attempt to bring the dynamic of local initiatives into line with the interests of public authorities and to reproduce the image of the state as being the key to development (Long and van der Plog 1989). Policy makers' most fundamental belief is that Western scientific knowledge has more authority and justification than so-called non-scientific, indigenous knowledge (Fairshed 1993).

According to our survey, local people think that domestic agricultural products are without a doubt superior to imported products, and they give a specific reason for the idea. In interviews when we ask farmers about the difference between domestic products and imported products, more than $90 \%$ of them talked about 'natural/chemical' differences. A farmer in Takaev (female in 40s) said, 'Our food is better and more delicious than imported foods. Imported foods are cheap because 
they are frozen and contain chemical substances'. Other farmers made statements as follows.

Governments have to devise innovative strategies to deal with the innumerable risks to health and well-being. In this paper, the author presents a description of the cases that have caused a contextual, political and economic redefinition of domestic/foreign (self/other) which goes beyond the conventional agricultural and industrial modernization process. According to Beck (1992), postmodern society is facing a new state of human insecurity characterized by the fear of the dark side of progress. Because of the failure of modern social institutions to control the risks they created, risk rebounds as a largely defensive attempt to avoid new problems. Here, the term risk is used simply as a synonym for hazard or danger. However, he also discusses a perspective in which risk is viewed as socially constructed and mediated through the lens of social and cultural processes; he says, 'It is cultural perception and definition that constitutes risk' (Adam, Beck and Loon 2000).

'Cambodian food is better than imported food because we use natural fertilizer, and the quality is good and standardized. The Cambodian government needs to conduct broader media advertising to cultivate people's trust and to validate the authenticity of our products' (male farmer in $60 \mathrm{~s}$, Kompot). 'Agricultural products imported from Vietnam use chemical substances, so they're cheaper than Cambodian products' (female seller in '40s, Kompot). 'The price of Thai chicken is $\mathrm{KHR} 10,000 / \mathrm{kg}$. Khmer chicken is KHR15,000/kg. Thai chicken is cheaper because it uses chemical substances' (female farmer in 40's, Kampong Speu). 'Cambodian products contain no poisonous substances, no chemical substances. Moreover, Cambodians always suspect imported products might use chemicals. But, we never see it with our own eyes. For example, young fruit can be ripened very fast by using chemicals' (female seller in 60's, Sihanoukville).

Thus, for Cambodian people, the differences between domestic and imported products are closely related to the 'image' of chemicals regardless of whether chemical substances are present or not. Therefore, we can call these products whose perceptions are based on images 'imagined domestic and imported products'. Although they are imagined, they are 'a reality' for local people. In addition to this, rumors spread by Khmer farmers and immigrants about foreign agricultural products also give a boost to Khmer products' value in Cambodian society. For example, there are many rumors in rural areas where immigrants engaged in agriculture abroad speak to relatives and friends about agriculture, saying that uses 
a great number of chemical fertilizers and pesticides, and these rumors also become a part of the elements that form the image of Cambodian versus foreign products.

In the survey, a farmer (in 70s) in Kampot said, 'We need to produce good quality, hygienic, "not fake" agricultural products when we compete with other countries" products'. Another farmer (in 30s) in Kampot added, 'The government should directly go to the fields and check the quality to attract Cambodians and foreigners to Khmer products'. These narratives show that people believe that the natural, authentic Cambodia products are competitive due to their quality in the international market, creating a growing call for the certification of authentic products. As presented above, these perceptions were constructed by the everyday risk experience, rumors, and 'education' by the government and NGOs about food risk. Also, these perceptions are not based on scientific evidence but are socially constructed, mediated through the lens of social and cultural processes in local society.

\section{Conclusion: Controlling Risk and Uncertainty}

Twenty-three years have passed since the end of the twenty-year civil war and the state's return to normality and further progress has been achieved in social and economic development. In the survey interview, a male farmer in his 40's in Takaev said, 'We have restarted and rebuilt our life from the point where there was nothing after the civil war. At that time, we lost not only material things but also people's lives, so for even, it was difficult to find what we have'. He added, 'The current meaning of development is different from the previous one. Just after the war, we needed everything that the government and the international community provided to us. We could not stand on our own feet economically yet, but now we have food, clothing, cattle for farming and motorbikes. Now is the time to tell them to support what we need. This means that the methods and the needs of development have changed'.

As his statement shows, after the war's chaos, most Cambodians started to rebuild their community and their livelihood in a shortage of foods and other daily necessities. At the state level also, the government has begun the national building without key domestic industry, which means that Cambodia has no industries to protect and it sought a way to reintegrate into the international community. This was one of the reasons why Cambodia achieved an early accession into the WTO. However, the times and social circumstances are changing; the pace of globalization, including the flow of people, commodities, and information, is 
accelerating year after year. Moreover, as has been described in this paper, some farmers are trying to ride the wave of globalization and capitalism to improve their livelihood, and the new social changes that have emerged in recent years have the potential to contribute to the national economy.

People live with economic practice - producing, distributing, buying, selling and consuming, which have been historically and culturally shaped. These practices are fraught with uncertain elements such as quality, amount, production region and also the changing environment; therefore, people need to deal with uncertainties and risks, and so they acquire the skills to control and avoid problems caused by the nature of the uncertainty. In that uncertainty, they evaluate products from their appearance, taste, smell, and the speed of deterioration. These physical practices have formed buying and selling customs, which are peoples' strategies to manage the uncertainties of everyday trade. In recent years, the flow of commodities has accelerated because of globalization, and the risk from a series of health hazards caused by border trade has enhanced people's health consciousness. Traditionally, people establish personal relationships with sellers to get reliable information about the products, including food, to control risk. These days, the circumstances have made it difficult to control the large quantities of commodities. As a result, demands are growing for 'certainty' regarding products, such as trademarks or certification by the government or international institutions.

Dramatic changes in the economy after the civil war provoked not only changes in agricultural production but also the buying-selling customs embedded in local society. These developments certainly carry costs that could be heavy, like increased risk and uncertainty. However, the same forces also are bringing new opportunities and values, and many Cambodian people are responding positively to accommodate them. Cambodia still has many obstacles to expand trade internationally. In contrast, many farmers believe that domestic agricultural products are worth more than similar products in other countries and that they have strong competitiveness in the international market. Moreover, most of them desire to take advantage of buying-selling opportunities to enhance their living standards.

Concerns exist about the trade issues, especially risk posed by it, in the specific socio-historical context and continued observance when policies are implemented in local society remains important, including observation of how the policies reflect the complexities and ambiguities of 'realities', experiences, and perceptions of the people who they are intended to serve. 


\section{Acknowledgement}

This research was partially supported by Institute of Developing Economies and the Ministry of Education, Science, Sports and Culture, Grant-in-Aid for Young Scientists(18K12590). I thank all my informants and friends in Cambodia who provided insight and expertise that greatly assisted the research.

\section{References}

Adam, Barbara, Ulrich Beck and Joost Van Loon. 2000. The Risk Society and Beyond: Critical Issues for Social Theory. London, Thousand Oaks and New Delhi: Sage Publications Ltd.

Beck, Ulrich.1992. Risk Society: Towards a New Modernity. London, Thousand Oaks and New Delhi: Sage Publications Ltd.

Yu, Bingxin, and Xinshen Diao.2011. Cambodia's Agricultural Strategy: Future Development Options for the Rice Sector. Phnom Penh: CDRI.

Delvert, Jean.1961. Le Paysan Cambodgien. Paris: Mouton.

Douglas, Mary.1983. Risk and Culture: An Essay on the Selection of Technical and Environmental Dangers. Berkeley: University of California Press on Demand.

Fairshed, James.1993. "Representing Knowledge: The "new farmer" in research fashions'. J. Pottier(ed.) Practicing Development: Social Science Perspective. London: Routledge. pp.187-204.

Giddens, Anthony.1999. Risk and Responsibility. The Modern Law Review Vol. 62. pp.1-10.

Kem, Sothorn, Chhim Chhun, Theng Vuthy and So Sovannarith. 2011. Policy Coherence in Agricultural and Rural Development: Cambodia. Phnom Penh: CDRI.

Long, Norman.1996. 'Globalization and localization New challenges to rural research'. H. Moore(ed.)The future of anthropological knowledge. London: Routledge. pp. 37-59.

Long, Norman, and Jan Douwe van der Ploeg. 1989. 'Demythologizaing Planned Intervention'. Sociologia Ruralis 29(3/4). pp. 226-249.

MAFF. 2012. Annual Report for Agriculture Forestry and Fisheries 2011-2012. Phnom Penh: MAFF.

Nimol, Tep, and David Boyle. 2010. "PM Takes firm stand on disease". The Phnom Penh Post. August 5, 2010. http://phnompenhpost.com (accessed December 
$10,2013)$

Smith, Noel, Andreas Cebulla, Lynne Cox and Abigail Davies. 2006. 'Risk Perception and the presentation of Self: Reflections from Fieldwork on Risk'. Forum: Qualitative Social Research. 7(1). Art.9. http://nbn-resolving.de/urn:nbn:de:0114fqs060191.

Tulloch, John, and Deborah Lupton. 2003. Risk and Everyday Life. London, Thousand Oaks and New Delhi: Sage.

World Bank. 2006. World Development Report2006. Washington, DC: World Bank.

. 2012. World Development Report2012. Washington, DC: World Bank. 